\title{
Compreensão do Distúrbio Psicossomático a Partir da Vivência de Médicos
}

\author{
Vera Lucia Pereira Alves* \\ Espaço de Estudos e Pesquisas na Abordagem Centrada na Pessoa Dr. John Keith Wood, Campinas, Brasil
}

Tatiana Gomez Espinha*

Faculdades Atibaia, Atibaia, Brasil

\begin{abstract}
RESUMO
Com o objetivo de conhecer a vivência de médicos no atendimento de pacientes por eles considerados psicossomáticos, foi realizada uma pesquisa qualitativa de perspectiva fenomenológica em que quatro profissionais foram entrevistados. Como resultado, os médicos não referiram formação teórico-prática sobre o tema, mas apontaram para um conhecimento construído a partir de suas experiências clínicas, em função de como entendem: a formação do sintoma; a caracterização destes pacientes e as doenças consideradas psicossomáticas e o tratamento vislumbrado. Estes médicos refletiram o mesmo mosaico conceitual encontrado entre os estudos científicos de psicossomática os quais revelam a temática atravessada pelo raciocínio determinista do modelo biomédico. Conclui-se que novos modelos são necessários tanto no campo da medicina como da psicossomática.
\end{abstract}

Palavras-chave: medicina psicossomática; relações médico-paciente; educação médica; pesquisa qualitativa.

\section{ABSTRACT \\ Understanding of the Psychosomatic Disorder from the Experience of Physicians}

With the aim of knowing physicians' experience in the assistance of patients considered by them as psychosomatic, a qualitative and phenomenological research was done with four doctors. As a result, the doctors didn't report any theoretical-practical formation on the theme, but pointed to a built knowledge based upon their clinical experience, as they understand: the formation of the symptom; the characterization of these patients and the disorders considered psychosomatic and their due treatment. These doctors reflected the same conceptual mosaic found among scientific studies on psychosomatics, which reveal such thematic crossed by the biomedical model's deterministic thinking. It is concluded that new models are as necessary in the field of medicine as in that of psychosomatics.

Keywords: psychosomatic medicine; physician-patient relations; medical education; qualitative research.

O exercício da atividade de Psicologia Hospitalar, bem como todo um contexto de trabalho mais amplo, igualmente alinhado à Psicologia da Saúde, aguçou o interesse em explorar como se dariam as vivências de médicos - também atores deste contexto - em um campo identificado como centralizador da dimensão psicológica: a Psicossomática. Deste modo, o presente estudo objetivou compreender como médicos com atuação em diversos contextos de atenção à saúde compreendem pacientes que consideram psicossomáticos. Como esta compreensão se dá? Como se sentem ao atender um paciente assim identificado?

O termo Psicossomática, como definem vários estudiosos do assunto (Cerchiari, 2000; Lyketos, Huyse, Gitlin \& Levenson, 2006; Aisenstein, 2008 e Figueira \& Ouakinin, 2008), surgiu em 1818 com os estudos de

* Endereço para correspondência: Vera Lucia Pereira Alves - vera@alves.com.br

* Endereço para correspondência: Tatiana Gomez Espinha - tagomez8@hotmail.com 
Heinroth. Contudo, foi deixado de lado e somente nas primeiras décadas do século $\mathrm{XX}$ voltou à tona (Cerchiari, 2000; De Marco, 2003), com a introdução da expressão Medicina Psicossomática, feita por Deustsch em 1922 (Turato, 2008; Lyketsos et al, 2006 e Hoyos, Ochoa \& Londoño, 2008).

A Psicossomática, em seu sentido ideológico, é o campo que versa sobre o estudo da dinâmica psicológica do adoecimento. Mostra-se como uma moderna e ampla área de conhecimento teórico e de práticas que objetivam o estudo e o tratamento de pessoas "cuja característica comum e principal é a apresentação de queixas somáticas inespecíficas ou difusas em que falta uma base orgânica que as justifique e nas quais os fatores psicológicos são vistos como etiologicamente relevantes" (Fortes, Brasil, Garcia-Campayo, \& Botega, 2006, p. 305).

Alguns autores apontam para as diferenças de significado entre as expressões doenças Psicossomáticas e Medicina Psicossomática. Consideram que a primeira refere-se à compreensão sobre as doenças em que aspectos emocionais se fazem presentes como causa e/ou elemento de sua evolução (Turato, 2008), enquanto a segunda, para Sami-Ali (1992), levanta a introdução de variáveis psicológicas no domínio do orgânico. Tem sido sob estas expressões e seus correlatos mais atuais que, como referido anteriormente, desde o século XX se estuda a interligação entre aspectos psicológicos e orgânicos, interligação esta que começou a ser compreendida a partir da concepção psicanalítica.

A Psicossomática desenvolveu-se em estrita ligação com a teoria de Freud, mesmo que ele jamais tenha escrito uma teoria sobre o tema, talvez por guardar proximidade com seu conceito de conversão - uma vez que ambos os processos se expressam fisicamente (Turato, 2008). Como aduzem Aisenstein (2008) e Boschan (2007), foi sob as observações iniciais de outros psicanalistas, como Deutsch, Groddeck e Ferenczi que a disciplina se desenvolveu.

Na década de 1930, nos Estados Unidos, foi criado o Instituto de Medicina Psicossomática de Chicago. Franz Alexander, seu representante, lançou, em 1950, a obra Psychosomatic Medicine em que buscava conceber a doença psicossomática como decorrente de estados de tensão interna: conflitos não plenamente elaborados que passavam a ser expressos pela via corporal (Cerchiari, 2000; Volich, 2000; Turato, 2008; Boschan, 2007).
Segundo Turato (2008), o trabalho de Alexander guardava semelhança com a hipótese de perfis psicossomáticos delineados anteriormente por Flanders Dunbar em sua obra Psychosomatic Diagnosis, de 1943, na qual descreveu estes perfis em associação a aspectos psicológicos específicos subjacentes a determinadas doenças. $\mathrm{O}$ entendimento acerca de características pessoais fundamentando algumas doenças só foi possível, segundo Capitanio (2008), exatamente pela incorporação da Psicossomática pelo campo da Medicina.

Na década de 1970 foi fundada a Escola Psicossomática de Paris, com Pierre Marty, Michel de M'Uzan, Michel Fain e Chistian David, que, partindo de concepções psicanalíticas, notadamente da metapsicologia, desenvolveu, desde a década de 1950, uma compreensão de Psicossomática em que a função do aparelho psíquico regularia o funcionamento psicossomático (Cerchiari, 2000; Volich, 2000).

As duas escolas representadas pelos institutos supracitados apresentam-se como grandes marcos na história da Psicossomática, em que as ideias da Psicanálise se fazem presentes. Em alinhamento à compreensão de Mello Filho (2002), para quem a evolução da temática ocorreu em três fases, esta seria uma primeira - a psicanalítica -, baseada em conceitos como inconsciente, regressão e ganho secundário, entre outros, provenientes das ideias de Freud e seus seguidores.

A segunda fase representaria uma concepção baseada em conceitos behavioristas, marcada notadamente pelos estudos sobre stress iniciados por Hans Selye e que, para De Marco (2003), deram origem à abordagem atualmente denominada psicofisiológica, em que se agrupam estudos acerca dos mecanismos neurofisiológicos, neuroendocrinológicos e imunológicos que, decorrentes de estados mentais, provocariam mudanças orgânicas.

A terceira, e atual, fase estaria sublinhada pela multidisciplinaridade que valoriza a compreensão de aspectos sociais, bem como integra os estudos de profissionais de diversas áreas de saúde.

Em outra linha de compreensão - subdividida não por fases, mas pela via das conotações incorporadas pela Psicossomática em seu desenvolvimento - é possível pensá-la como fundamentada na noção de psicogênese ou de holismo segundo Lipowski (1986). A primeira noção é condenada por ele porque torna incompatível a multicausalidade, postulado central da 
atual Medicina Psicossomática - a terceira fase - na visão de Mello Filho.

A vertente da psicogênese opera de acordo com a crença de que os fatores psicológicos causam doenças orgânicas: as emoções influenciam o funcionamento corporal, podendo adoecê-lo. Trata-se de uma vertente que Rovaletti (2002), De Marco (2003) e Hoyos et al. (2008), consideram alinhada ao dualismo cartesiano. Mesmo que se considere a psicossomática como uma forma de reação contra este dualismo, cujo foco predominante está no estudo do corpo, ambos - psicogênese e cartesianismo - operam a partir desta distinção, o que, para De Marco (2003), seria diferente na concepção holística por pressupor a unidade mente/corpo. Porém, para ele, esta concepção se faz presente muito mais na teoria do que propriamente nas práticas deste campo.

Constata-se assim que o fenômeno psicossomático vem sendo compreendido conjuntamente com os referencias teóricos e metodológicos daqueles que o estudam e, consequentemente, vêm sendo geradas conceituações também diversas (Guedes, Nogueira, \& Camargo Jr, 2008). Como afirmam De Gucht e Fischler (2002), apesar das diferenças, o elemento comum em todas as conceituações é a presença de sintomas que não se explicam por achados orgânicos, os quais ela conclui desenvolverem-se usualmente de três formas: 1) como expressão somática que implica relação causal entre a somatização e as emoções; 2) como categoria diagnóstica em que múltiplos sintomas se alinham a diversos órgãos e; 3) como síndromes somáticas funcionais em que sintomas específicos são agrupados (De Gucht \& Maes, 2006).

Esta terceira forma parece ter resultado, de alguma maneira, na atual nomenclatura dos fenômenos psicossomáticos, como demonstram Coelho e Ávila (2007), para quem a histeria e os informais "piripaques" dos meios médicos e psicológicos têm sido atualmente referidos por transtornos somatoformes ou sintomas médicos inexplicados, que são, por sua vez, agrupados sob a nomenclatura síndromes funcionais ou síndromes somáticas funcionais quando apresentadas por indivíduos com queixas físicas cuja origem orgânica não se demarca, já que os indicadores biológicos estão ausentes (Hartman, Lucassen, Lisdonk, \& Weel, 2004; Kanaan, Lepine, \& Wessely, 2007; Pilan \& Beseñor, 2008).
Para Bombana (2006), estas terminologias - correlatos atuais do termo Psicossomática - também se diferenciam em virtude dos profissionais e/ou das áreas que as utilizam. Na psiquiatria, faz-se uso do termo transtornos somatoformes, enquanto na clínica médica, síndromes somáticas funcionais. Todavia, dentro das mesmas especialidades, os termos podem ter usos controversos, como apontam Tófoli, Andrade e Fortes (2011), no caso do termo transtornos somatoformes na psiquiatria.

Em artigo sobre o tema, Figueira e Ouakinin (2008) referem à falta de concordância para definir o conceito de Medicina Psicossomática como algo internacionalmente constatado e que resulta em visões e domínios diferentes. Na Europa, a Medicina Psicossomática é diferente da estabelecida nos Estados Unidos, onde se tornou, na década de 2010, subespecialidade da psiquiatria.

No Brasil, segundo De Marco (2003) e Mello Filho (1992), o termo Psicossomática designa um vasto campo de atividades dentro da área de saúde, mais especificamente nas ciências médicas e psicológicas.

Para Mello Filho (1992), sob este conceito agrupam-se desde atividades de ensino e/ou práticas de saúde até os cuidados com as relações entre médico, pacientes e familiares. Atividades que se concretizam em práticas de saúde que, como constatado, comportam compreensões difusas e terminologias diversas, além de continuamente marcadas pelo cartesianismo, fato que dificulta uma melhor compreensão do indivíduo e, por conseguinte, uma atuação mais integrada, como também concorda Dantas (2011).

O pensamento de Descartes, desde o século XVII, origem do paradigma cartesiano, é a principal influência do modelo que alicerça toda a moderna medicina científica. A ideia fundante é a separação mente/corpo. O corpo, ou a matéria, é explicado de acordo com princípios mecânicos, comparando-o ao funcionamento de uma máquina. Já a mente, instância separada, dá movimento ao corpo, mas de maneira puramente mecânica. Haveria, ainda segundo Descartes, uma interação entre ambos, porém de difícil junção, novamente e de forma harmônica (Heidbreder, 1981).

Postura esta, presente na atual prática médica, caracteristicamente vinculada ao modelo biomédico que referenda toda uma atuação pautada na detecção da moléstia e em sua consequente classificação nosológica: bases fundamentais para a efetivação do tratamen- 
to que, por conseguinte designa à Medicina interpretar a doença como um desvio de variáveis em relação à norma, mesmo que abrindo espaço para a Psicossomática que, em tese, quer como disciplina, ideologia, teoria e/ou prática, tem como meta a visão integrada do paciente e o interesse pela constatação de sua subjetividade junto ao problema somático expresso.

Para vários autores (Cerchiari, 2000; Rovaletti, 2002; Turato, 2008; Trombini \& Baldoni, 2004; Bombana, 2006; Hoyos et al, 2008; Fava \& Sonino, 2009, Schwartz \& Wiggins, 2010; Dantas, 2011), as práticas que vêm sendo utilizadas sob a égide da Psicossomática, bem como sua teorização, não têm dado conta desta meta. Trata-se, por vezes, de uma compreensão e teorização que toma por ponto de partida o próprio referencial da Medicina, qual seja, a relação de causalidade entre doença e lesão, o que denota, como leciona Guedes et al. (2008), que o termo sintomas médicos inexplicáveis são assim denominados em função dos próprios limites do modelo biomédico para explicá-lo. Estes sintomas, segundo os autores, "ludibriam o princípio fundamental da biomedicina" (p. 138).

Compreender algumas entidades somáticas com gênese psicológica ou eventos orgânicos influenciando processos psicológicos implica manter a dualidade corpo mente, vista tanto na Medicina Psicossomática quanto na Psicofisiologia (Trombini \& Baldoni, 2004; Dantas, 2011). Postura que, segundo Fava e Sonino (2009), Engel já criticava, pontuando que se compreendemos a Psicossomática mantendo esta dualidade, e principalmente a ideia de psicogênese, deveríamos conceber, então, por inferência, a ausência de interface psicossomática em outras doenças não assim designadas.

Mediante um mosaico tão complexo de compreensão e práticas afeitas e/ou conceituadas em acordo a diferentes entendimentos de Psicossomática interessou-nos conhecer e compreender a vivência de médicos junto a pacientes assim considerados.

\section{MÉTODO}

A fim de compreender as questões inicialmente colocadas como objetivo deste estudo optou-se pelo uso de metodologia de pesquisa qualitativa de tipo fenomenológico.

A pesquisa qualitativa, segundo Palmieri (2005), envolve a obtenção de dados descritivos provenientes do contato direto do pesquisador com a situação estudada, preocupando-se mais com o processo que com o produto, e enfatizando a perspectiva dos participantes e seus significados. E como a pesquisa fenomenológica em Psicologia tem por objetivo principal captar o sentido de uma vivência imediata para uma pessoa em uma determinada situação (Forghieri, 2002), este modelo mostrou-se adequado ao propósito do estudo: compreender a vivência de médicos que atuam em diferentes contextos de saúde ao atender pacientes considerados, por eles, psicossomáticos.

As entrevistas foram de tipo aberta e iniciadas com um convite/pergunta disparadora:

Estou fazendo uma pesquisa sobre processos psicossomáticos. Por saber que se trata de um campo complexo em que se mesclam conhecimentos de medicina e psicologia, eu gostaria de saber como é sua experiência nesta área. Como foilé para você atender uma pessoa com este diagnóstico?

No decorrer da entrevista, teve-se o cuidado de transitar por temas pré-estabelecidos que, se não fossem abordados diretamente pelo entrevistado, lhes seriam questionados no momento mais adequado de seu discurso. De forma geral, estes temas permeavam os seguintes aspectos:

- Como ele lida com o paciente?

- Como ele percebe o paciente?

- Como ele se mobiliza emocionalmente com esta situação? e

- Qual a aprendizagem anterior sobre o assunto?

As pesquisadoras e autoras do projeto, psicólogas com experiência na metodologia, foram as entrevistadoras. A realização das entrevistas foi precedida de um contato inicial em que foram explicados, de maneira clara, o objetivo e os procedimentos adotados. Após o consentimento do entrevistado, foram marcados hora e local adequados para a realização do procedimento, iniciado somente após a leitura e assinatura do Termo de Consentimento Livre e Esclarecido por parte do entrevistado, bem como do esclarecimento de dúvidas, conforme a Resolução 196/96 do CONEP/CNS. Utilizou-se um gravador como meio de registro das entrevistas, que posteriormente foram transcritas. O projeto de pesquisa foi aprovado pelo Comitê de Ética da Pontifícia Universidade Católica de Campinas sob número 604/06. 


\section{Participantes}

O critério de inclusão dos participantes foi estabelecido em função dos diferentes contextos de trabalhos, uma vez que o objetivo da pesquisa era captar a vivência de médicos procurados por pacientes nos diversos momentos de atenção à saúde, sejam atendimentos de urgência no hospital, sejam consultas eletivas em ambulatório ou consultório, tanto público quanto privado e que já tivessem atendido pacientes considerados por eles psicossomáticos.

Deste modo, participaram desta pesquisa quatro médicos que atendiam pacientes considerados por eles como psicossomáticos. Cabe ressaltar que as vivências relatadas pelos participantes possibilitaram a reincidência de suas informações, ou seja, a caracterização de suas vivências (Minayo, 2010), uma vez que os elementos relatados atingiram o critério de saturação teórica (Turato, 2008).

Foram utilizados nomes fictícios para identificar os participantes, a fim de preservar suas identidades: Rosa, Marina, Alfredo e Gabriel.

Rosa tinha treze anos de formada e trabalhava, no momento das entrevistas, em ambulatório, consultório e hospital particulares, tendo já trabalhado no serviço público. Marina, com seis anos de formada, já havia trabalhado em consultório privado e centros de saúde e, à época da entrevista, trabalhava em um prontosocorro privado. Alfredo foi o entrevistado com maior tempo de formado: 27 anos. Na época da entrevista, trabalhava como clínico em ambulatório e como cirurgião, tanto em serviço público quanto privado. Gabriel tinha 22 anos de formado e trabalhava em ambulatório, pronto-socorro e também como cirurgião no serviço público e privado.

\section{Procedimento de Análise}

As entrevistas foram analisadas segundo o método fenomenológico, tendo como base a proposta feita por Amatuzzi (2003), numa reformulação do método desenvolvido por Amedeo Giorgi (2009), e, que segue os seguintes passos:

- A partir de uma leitura cuidadosa da transcrição de cada entrevista, extraiu-se o significado da vivência, buscando, na expressão do vivido, respostas ao problema de pesquisa.

- A seguir, agruparam-se os elementos do vivido de cada entrevista que foram encontrados na etapa anterior, de acordo com afinidades temáticas.

- Cada um dos agrupamentos temáticos foi descrito visando à elaboração posterior da síntese geral.

- Por fim, elaborou-se uma síntese geral do vivido, na qual constavam os elementos comuns e diferenciados vivenciados, encontradas nas entrevistas.

Os resultados obtidos permitiram construir duas grandes áreas de estudo: a compreensão do fenômeno psicossomático pelos médicos e a forma de atuação com estes pacientes. Este último tema será apresentado em publicação posterior. Os resultados que seguem mostram a compreensão de psicossomática pelos participantes da pesquisa.

\section{RESULTADOS E DISCUSSÃO}

Os entrevistados ao descreverem suas vivências no atendimento dos pacientes que consideram psicossomáticos nos permitiram perceber e compreender como eles constroem suas compreensões do fenômeno psicossomático. Compreensão esta apresentada abaixo acompanhada de uma discussão que se alinha ao histórico e panorama da temática traçados na introdução. A compreensão do fenômeno psicossomático apresentada aqui destaca três aspectos centrais que se encontram totalmente interligados. Trechos das falas dos entrevistados são apresentados de forma a ilustrar a descrição e a discussão desenvolvidas.

Os médicos afirmam ter uma compreensão do fenômeno psicossomático fruto de construção prática, não proveniente de estudos mais sistematizados ou acadêmicos, em que, por vezes, se fazem presentes conhecimentos da esfera do senso comum e/ou divulgados pelas mídias em geral.

Eles evidenciam em seus relatos como constroem a compreensão daquilo que consideram ser um fenômeno psicossomático e, para tanto, apontam três aspectos que se encontram totalmente interligados: a) como consideram ser formados os sintomas psicossomáticos e quais fatores permeariam esta formação; b) como diagnosticam ou caracterizam estes pacientes a partir da percepção que deles têm e, por conseguinte, quais patologias consideram psicossomáticas e; c) como pensam ser o tratamento ou a "cura". 
A compreensão evidenciada é diversificada, no entanto é absolutamente semelhante quanto ao fato de ser descrita e obtida especificamente por meio da compreensão da postura do paciente. Mesmo que os entrevistados descrevam fisiologicamente o mecanismo da somatização, ela é sempre demonstrada e exemplificada pelo modo como entendem a expressão do paciente, quer seja pelas suas queixas, quer pelo modo como se expressa na consulta.

Em muitos momentos, os entrevistados mostram ter dificuldade em entender ou "desvendar" a expressão do paciente, uma vez que ela é diferente do habitualmente conhecido por eles: são queixas físicas que não permitem identificar causas orgânicas. Assim, passam a compreender que aquilo que causa a formação dos sintomas e configura então uma situação psicossomática quase sempre estaria ligado a questões emocionais. De maneira mais específica, Rosa e Alfredo relatam que as causas podem estar conectadas a problemas mal resolvidos na infância ou a desgraças acontecidas na vida de uma pessoa, principalmente quando pensam nos pacientes que frequentam o serviço público de saúde.

O entendimento que Gabriel relata é o mais detalhado fisiologicamente e, assim como o de Alfredo, demonstra o mesmo raciocínio biomédico para a compreensão do evento psicossomático: as emoções produzem substâncias que são descarregadas no corpo e podem gerar determinados tipos de doenças. Para eles, e também para Rosa, que, entretanto, não apresenta estas digressões, o fenômeno psicossomático compreendido pela via da psicogênese, é decorrente de um estresse, de um momento em que o paciente vive algo que não consegue elaborar ou, como eles dizem, "quando o paciente não está compensado", quando "um problema foi puxando outro". A consequência será o que Gabriel afirma sob forma de pergunta: "se você tem uma patologia, se você estivesse nervosa bate o cotovelo não dói mais do que se você estivesse tranquila e bate o cotovelo?" O que ele e Alfredo constatam acontecer neste momento é o surgimento da ansiedade e a diminuição da tolerância: " $A$ ansiedade piora muito. Você tem que diminuir o limiar de tolerância. Quando a pessoa está ansiosa, o limiar de tolerância dela baixou" (Gabriel).

Alfredo mostra, então, a compreensão fisiológica deste quadro:

Mas é assim que funciona. Por exemplo, você fica nervosa e você libera acetilcolina. Essa substância no estômago libera excesso de ácido clorídrico. Quando esse ácido tem que ser liberado? Quando tem alimentação. Essa acetilcolina não teria que vir em excesso e ela vem em horário que não tem comida. Por quê? Porque a pessoa está lá nervosa, ansiosa, angustiada ou magoada. Então, todo estado psicossomático leva a uma doença física por liberação de substâncias seja ela qual for.

Rosa resume esta mesma compreensão funcional do estado que nomeia por estresse e a partir dela passa a olhar um novo paciente: "Na primeira consulta, eu já falo: 'sua falta de ar muito provavelmente é uma reação ao estresse, isso é uma coisa que você tenta colocar pra fora através do pulmão".

São também as palavras e conceitos de Gabriel que permitem acreditar que, talvez, para estes médicos, a compreensão do fenômeno psicossomático siga igualmente os postulados do raciocínio biomédico. Ele traça sua compreensão ou discriminação sobre um processo psicossomático em função da ausência de lesões. Para Gabriel, a somatização é uma patologia funcional, e não estrutural (em que há lesão): " $E$ quando a pessoa está com alguma alteração, como um problema emocional, parte da puberdade, por exemplo, problemas pessoais; aí desencadeia esse tipo de processo; a patologia funcional".

Como consequência deste raciocínio, eles mostram uma compreensão geral de quem são estas pessoas, referendada pelo contexto percebido do paciente, seu estado e seu jeito de ser. A caracterização destes pacientes, mais o descarte de problemas orgânicos por meio de exames físicos realizados de início, constituem para estes médicos os elementos centrais do "diagnóstico", considerando-os psicossomáticos, que, como apontado por Rosa, conta também com uma ideia acerca de quais doenças já são consideradas psicossomáticas. Obesidade, diabetes descompensada, hipertensão, lúpus, falta de ar, tendinite e dor muscular fazem parte das categorias diagnósticas apresentadas por eles como de ordem psicossomática. Dentre elas, há doenças, tais como os distúrbios digestivos, as alergias e as enxaquecas, que desde o trabalho inicial de Alexander já compunham o grupo de entidades nosológicas que são sempre as lembradas como psicossomáticas (Turato, 2008).

As doenças referendadas portam os elementos que De Gucht e Fischer (2002) elencam, como já apontado, na configuração das três expressões da psicossomática na medicina: relação causal, categoria diagnóstica e constituição de síndromes. 
Constata-se também que estes médicos apontam agrupar tanto doenças, como sua evolução (o "descompensar" da diabetes) e sintomas para compor a esfera psicossomática. Este fato também não parece diferir do que é encontrado na literatura científica acerca das doenças psicossomáticas. O Artigo de Ávila (2006) aponta já em seu título para uma questão da temática a ser refletida: trata-se de somatização ou de sintomas psicossomáticos? A atual terminologia, de igual forma, indica por vezes os sintomas - medicamente inexplicados -, por vezes os transtornos ou as síndromes, elencando ainda a fibromialgia e a síndrome da fadiga crônica que, dentre outras, são também as que surgem debatidas com mais frequência na mídia impressa, como apontam Alves, Lima, Rivorêdo e Turato (2013).

Os portadores destes sintomas e/ou destas doenças, de forma geral, são vistos por estes médicos como difíceis, carentes de atenção e assíduos frequentadores dos serviços médicos. Para Rosa, por exemplo, este tipo de paciente é mais difícil de tratar do que aquele que tem uma doença física mais complicada. Para Marina, essas pessoas são mais difíceis (chatas) e diferentes dos demais pacientes, exigindo mais do médico, o que faz com que ela os encaminhe para outro profissional que, conforme ela, também não resolve o problema. Já para Gabriel, essas pessoas são mais difíceis, pois chegam ao consultório quando a situação está bastante crítica.

Marina aprofunda seu entendimento fazendo referência a outro elemento que compõe a compreensão acerca de problemas considerados psicossomáticos. Trata-se da ideia de que estes pacientes são pessoas que não querem mudar a situação da doença que estão vivendo, para não perder a atenção que ganham: "Você não consegue fazer o cara melhorar, fazer o cara entender que não é só tomar o remédio e que ele tem que cuidar de outras coisas. Eles têm uma resistência muito grande".

Gabriel compartilha da mesma visão:

Tem o limiar de dor e tolerância da doença. Tem gente que tem o problema e vive assim mesmo e fazer o quê?! Tem gente que não suporta ter nada. Tem gente que gosta de estar doente, tem gente que prefere estar doente, tem gente que adora passar no hospital, tem gente que passa quatro, cinco vezes por mês no médico, era para estar internado então, ninguém passa quatro, cinco vezes por mês no médico.
Descrevem assim, com base em seus conhecimentos práticos, seus próprios "perfis de personalidade" para estes pacientes. Incorrem na prática que Volich (2000), Cerchiari (2000) e Turato (2008) dizem ser muito antiga, mas ainda presente na medicina: o destaque dado a um conjunto de características de ordem psicológica.

Todavia, esta caracterização do paciente, ao menos para Marina e Rosa, parece provocar-lhes uma oportunidade para que, de alguma forma, possam perceber-se a si próprias nas suas atuações. Elas, ao dizerem que um paciente é difícil, apontam entender a dificuldade como referida mais a si mesmas do que ao próprio paciente, tornando-se claro que a dificuldade de lidar com esse tipo de paciente que, além de exigir uma conduta diferenciada dos profissionais, pode, ainda, como vivenciou Rosa, colocar a responsabilidade da sua melhora no próprio médico.

Dos relatos dos participantes do estudo, apenas o de Alfredo faz menção à "solução" dos problemas que os pacientes lhes trazem. Nenhum outro entrevistado menciona "a cura" - ponto final do tratamento -, se esta ocorre ou não e como se dá. Alfredo parece acreditar que o aumento da autoestima do paciente é o que pode ajudá-lo, e este pode ser obtido tanto por meio de psicoterapia como da religião:

Você aumentando a autoestima da pessoa, né?! Porque a terapia em si pega o indivíduo e faz ele acreditar nele mesmo. Para que ele mesmo pense e repense e chega a uma conclusão. Daí ele fala; 'estou curado disso porque eu pensei e repensei'. É a mesma coisa. A gente faz uma terapia muito rápida. $E$ aí alguns vão e tentam e outros vão para a igreja cuidar da fé. Enfim, eu dou muito pouco calmante. Então, para cada caso eu abordo de forma diferente. Mas não com estudos especificamente. Foi o que eu encontrei de mais fácil e a gente vai fazendo experiências e vai vendo que as pessoas acabam melhorando até pelo relacionamento e o que ela ouve.

Alfredo também menciona terapêuticas como, por exemplo, a utilização de relaxamento e a indicação de viagens, que podem, segundo ele, diminuir a quantidade de algumas substâncias nocivas ao corpo que são liberadas por determinadas emoções. De maneira geral, a cura se dá, para ele, por meio de um cuidado com as questões psicológicas e/ou espirituais.

Não apenas para a compreensão do fenômeno psicossomático, o conhecimento que fundamenta a atuação destes médicos é algo que se constrói com base 
não em uma específica formação médica com conhecimentos científicos. A solução vislumbrada por Alfredo demonstra também a preponderância de um conhecimento de senso comum acerca do que é a psicoterapia e o decorrente processo de restabelecimento e autoconhecimento. A alternativa que ele encontrou parece ser não apenas as usuais da medicina, como a medicação (no caso o calmante), mas viajar, ir à igreja e elevar a autoestima. São recursos que refletem a conduta traçada de acordo com o raciocínio biomédico: encontrar causas e eliminar sintomas.

Simultaneamente, esta postura mostra a tentativa, não apenas de Alfredo, em trazer à tona a dimensão psicológica dos seus pacientes. Porém, eles repassam a responsabilidade dos cuidados dos aspectos subjetivos. Os outros médicos encaminham os pacientes considerados psicossomáticos para psiquiatras e psicólogos, não deixando claro se o tratamento realizado por eles continua ou não após este encaminhamento.

A suposta integração corpo mente, com a tratativa dos aspectos psicológicos do paciente se daria, caso seguisse as orientações, de forma em que o próprio paciente é que deveria "integrar seus tratamentos".

Explicações iniciais para a conduta destes médicos no manejo de pacientes considerados psicossomáticos podem abordar aspectos da formação daqueles. Caprara e Rodrigues (2004) e Ribeiro e Amaral (2008) afirmam como a formação médica valoriza essencialmente os aspectos biomédicos e, deste modo, não habilita os profissionais a lidarem com aspectos emocionais e culturais. Estudantes de medicina que se deparam com pessoas sem doenças orgânicas têm dificuldade em compreendê-las porque " $n \tilde{a} o$ são bons modelos de patologia e diagnósticos e, por sua complexidade, colocam à prova a competência do estudante em sua necessidade de objetivar, buscando certezas", segundo Ribeiro e Amaral (2008, p. 93).

Esta é, portanto, a mesma dificuldade retratada pelos participantes do estudo, que apontam a ausência de uma formação médica apropriada para o manejo destes pacientes. Alfredo relata que, na sua época, o curso de medicina era muito diferente do atual. "Hoje já está mais provado. Eu sempre acreditei. Era uma crença individual minha. Na faculdade não se falava nada" tanto que "fui adquirindo esse conhecimento ao longo de minha experiência. Mesmo porque eu me interessava e aí a gente vai percebendo. Hoje, existem trabalhos nessa área", mas ele afirma não ter contato com tais estudos.

Gabriel faz referência temporal semelhante à de Alfredo acerca dos conhecimentos obtidos na faculdade:

Ainda não estava muito na moda, mas já existia e depende muito do professor. A gente tem a sorte de pegar alguns professores que são mais ligados a isso, que lembra o médico que ele está tratando não de uma patologia e sim de uma pessoa. Então, cada caso é um caso. Então, você tem que saber que tem todo um contexto. Não havia uma disciplina específica, mas eu não me lembro direito como era passado.

As médicas relatam uma formação bem diferente, que porta, todavia, aspectos a considerar. Rosa e Marina, com cerca de uma década de graduadas, têm aprendizagem que possivelmente espelha a realidade de ensino de tantos outros médicos.

Rosa conta que no início do curso de medicina teve uma disciplina de psicologia hospitalar e, posteriormente, uma de psiquiatria, em que aprendia sobre diagnóstico e medicação. Apesar disto, afirma que os alunos não tinham maturidade para avaliar um ensino do qual discordavam, que incluía ter o paciente frente a um grupo de alunos e a necessidade de decorar textos, ao invés de refletir sobre eles.

Marina, por sua vez, relata que estudou psiquiatria com um professor que lhe possibilitou a experiência de hospital-dia e atendimento domiciliar, situações que classificou como importantes, sobretudo pela reflexão que faziam posteriormente em sala de aula. Sua aprendizagem parece ter sido oposta à de Rosa e aparece marcadamente presente na conduta relatada no decorrer da entrevista. Entretanto, sua vida acadêmica parece sofrer do mesmo vazio teórico/prático de Rosa, Gabriel e Alfredo, pois seu contato atual com a literatura de psicossomática advém da influência de sua irmã, de fontes não científicas: "ela me passa alguns artigos da internet. Eu me interesso muito, pois lido diretamente com isso no PS. Leio mesmo por curiosidade".

Os entrevistados mostram como é coerente que seus conhecimentos se atenham simplesmente ao que é popularmente divulgado sobre psicologia. Algo que, contudo não é exclusividade destes médicos ou do atendimento de pacientes psicossomáticos, pois como referem Ribeiro e Amaral (2008) "o médico, cada vez mais, será confrontado com o conhecimento divulgado pela mídia, nem sempre comprovado cientifica- 
mente e nem sempre entendido de forma adequada pelo paciente, mas que passa a fazer parte de sua cultura sobre saúde" (p. 96).

Deste modo, pode-se concluir em acordo a Giannoti (1998), para quem é errônea a ideia de que basta difundir conceitos de psicossomática entre os médicos. Esta postura, segundo o autor, não contempla as dificuldades mais complexas, ligadas à formação médica, à concepção habitual de doença e às questões de método tanto da medicina quanto da psicologia, que também precisam de reformulação. Exatamente como mostram as duas médicas participantes do estudo ao se referirem à experiência de uma prática que parece não ter se demorado na exploração do contato psicológico entre paciente e médico, mas sim se alongado na prática do contato médico intermediado pela medicação e/ou internação.

Além disto, segundo a mesma autora, as concepções de psicossomática ainda não se inseriram efetivamente na prática da Medicina e da Psicologia, sendo, por enquanto, um campo de pesquisa ou, muito provavelmente, também pelo quão recente é a entrada do tema na Medicina Brasileira. Segundo Eksterman (1992), o início do movimento psicossomático no Brasil aconteceu na década de 1950, tendo como alavanca médicos do Rio de Janeiro e São Paulo com interesse em estudar mais a Psicanálise, estruturando serviços e divisões que inseriam a psicossomática como uma especialidade da medicina.

Na tentativa de ampliar o fenômeno da compreensão que estes médicos constroem, pode ainda ser acrescentado outro aspecto a ser refletido: o mosaico construído no entendimento de pacientes psicossomáticos não parece se diferenciar muito do próprio mosaico composto pelos muitos e variados estudos que se debruçam sobre a temática, conceituando-a, definindo, propondo e discutindo estratégias para o manejo destes pacientes.

Dois estudos recentes ajudam a clarear o espelhamento destes mosaicos. Os autores traçam mapeamentos sobre o tema quanto às nomenclaturas e definições dadas aos sintomas, bem como aos critérios utilizados para o diagnóstico e relevância da temática abordada (Guedes et al., 2008) e quanto a classificação de transtornos somatoformes, síndromes funcionais e sintomas sem explicação médica na América Latina (Tófoli et al., 2011). Ambos confirmam a dificuldade em definir, delimitar, classificar e conceituar tais quadros, oriundos da noção de psicossomática, fato que tam- bém se constata com a leitura da diversidade de artigos e capítulos publicados tanto no Brasil quanto no exterior.

Em acordo a estes dois estudos, os participantes da presente pesquisa também evidenciam compreender que pacientes assim identificados por vezes padecem em virtude de aspectos sociais e condições emocionais. No entanto, estes aspectos são constatados como presentes apenas no momento de diagnóstico e relevantes para os encaminhamentos, não sendo abordados e considerados para o tratamento realizado por eles (Tófoli et al., 2011).

A dificuldade dos médicos em conceituar, diagnosticar e tratar as condições em que se encontram estes pacientes aqui constatada é igualmente referida no levantamento bibliográfico de Guedes et al. (2008) que, concluem que subjaz à mesma, "o modelo biomédico que possui poucas ferramentas para se deparar com a singularidade do sofrimento humano em sua dimensão fenomenológica experiencial” (p. 135).

\section{CONSIDERAÇÕES FINAIS}

Os participantes deste estudo revelam através de sua compreensão prática do fenômeno psicossomático, elementos apresentados nos estudos científicos como configuradores e/ou justificadores do mesmo, superados ou não pela evolução do estudo da Psicossomática. Todavia, parece ser significativo o fato de que, embora lhes faltem maiores conhecimentos científicos, eles refletem o mesmo mosaico que estudos científicos têm desenhado para a Psicossomática na tentativa frustrada de considerar a integração corpo mente, ensejada desde sua fundação, mas dificultada por um modelo biomédico em que o raciocínio determinista tem aprimorado tecnologias absolutamente essenciais e promotoras de vida, mas deficitárias de uma compreensão do sofrimento humano para além do que se constata objetiva e concretamente em seu organismo.

Neste cenário, cabe refletir acerca de que configurações são possíveis para o contexto da promoção de saúde que almeja inserir na prática médica a dimensão psicológica por via, muitas vezes, da clássica noção de Balint (1957/1975), que afirmava ser a droga mais frequentemente utilizada na clínica geral o próprio médico, ou seja, não importando apenas os medicamentos e tratamentos oferecidos, mas também a maneira como ele os oferece. Se estes médicos não se 
percebem preparados para tanto, se o modelo biomédico e a própria psicossomática não têm ultrapassado a dualidade, talvez novos modelos sejam necessários.

\section{REFERÊNCIAS}

Aisenstein, M. (2008). Beyond the Dualism of Psyche and Soma. Journal of the American Academy of Psychoanalysis and Dynamic Psychiatry, 36, 106-123. Retrieved from http://www. pep-web.org/document.php?id=jaa.036.0103a

Alves, V. Lucia Pereira, Lima, Daniela Dantas, Rivorêdo, Carlos Roberto Soares Freire de, \& Turato, Egberto Ribeiro. (2013). Emoção e soma (des)conectadas em páginas de revista: as categorias temáticas do discurso prescritivo sobre os fenômenos da vida e da doença. Ciência \& Saúde Coletiva, 18(2), 537543. Retrieved from http://www.scielo.br/scielo.php?script= sci_arttext\&pid=S1413-81232013000200025\&lng=pt\&tlng=pt. doi: $10.1590 / \mathrm{S} 1413-81232013000200025$

Amatuzzi, M. M. (2003). Pesquisa Fenomenológica em Psicologia. In M. A. de Bruns \& A. F. Holanda (Orgs.), Psicologia e Pesquisa Fenomenológica: Reflexões e Perspectivas (pp. 1725). São Paulo: Alínea.

Ávila, L. A. (2006). Somatization or Psychosomatic Symptoms? Psychosomatics, 47, 163-166. Retrieved from http://psy.psy chiatryonline.org/cgi/content/full/47/2/163

doi: 10.1176/appi.psy.47.2.163

Balint, M. (1975). O médico, seu paciente e a doença (2 ${ }^{\mathrm{a}}$ ed. R. Musachio, Trad). Rio de Janeiro: Atheneu. (Trabalho original publicado em 1957).

Bombana, J. B. (2006). Sintomas somáticos inexplicados clinicamente: um campo impreciso entre a psiquiatria e a clínica médica. Journal Brasileiro de Psiquiatria, 55(4), 308-312. Retrieved from http://www.scielo.br/pdf/jbpsiq/v55n4/a07v55n4 .pdf

Boschan, P. J. (2007). Body, mind and bonds. American Journal of Psychoanalysis, 67, 235-248. Retrieved from http://www. pep-web.org/document.php?id=ajp.067.0235a

Capitanio, J. P. (2008). Personality and Disease Brain, Behavior, and Immunity, 22(5), 647-650. Retrieved from http://www. ncbi.nlm.nih.gov/pmc/articles/PMC2493466/ doi: 10.1016/j.bbi.2008.02.002

Caprara, A., \& Rodrigues, J. (2004). A relação assimétrica médico-paciente: repensando o vínculo terapêutico. Ciência \& Saúde Coletiva, 9(1), 139-146. Retrieved from http://www.scielo sp.org/pdf/csc/v9n1/19831.pdf

Cerchiari, E. A. (2000). Psicossomática um estudo histórico e epistemológico. Psicologia. Ciência e profissão, 20 (4), 64-79. Retrieved from http://pepsic.bvsalud.org/scielo.php?script=sci_ arttext\&pid=S1414-98932000000400008\&lng=pt\&nrm=iso.
Coelho, C. L., \& Ávila, L. A. (2007). Controvérsias sobre a somatização. Revista de Psiquiatria Clínica, 34(6), 278-284. Retrieved from http://www.hcnet.usp.br/ipq/revista/vol34/n6/278. html

Dantas, J. B. (2011). Corpo e Existência: Outro modo de compreensão da psicossomática. Interação em Psicologia, 15(1), 7180. Retrieved from http://ojs.c3sl.ufpr.br/ojs2/index.php/psico logia/article/view/16262

De Marco, M. (2003). A face humana da medicina. São Paulo: Casa do Psicólogo.

De Gucht, V., \& Fischler, B.(2002). Somatization: A Critical Review of Conceptual and Methodological Issues. Psychosomatics, 43(1), 1-9. Retrieved from http://www.mendeley. com/research/somatization-critical-review-conceptualmethodological-issues-1/

De Gucht, V., \& Maes, S. (2006). Explaining medically unexplained symptoms: Toward a multidimensional, theory-based approach to somatization. Journal of Psychosomatic Research, 60(4), 349-352. Retrieved from http://www.jpsychores.com/ article/S0022-3999(06)00046-8/fulltext

Eksterman, A. (1992). Medicina Psicossomática no Brasil. In J. de Mello Filho (Org.), Psicossomática hoje. (2 $2^{\mathrm{a}}$ ed). (pp. 28-34). Porto Alegre: Artes Médicas.

Fava, G.A., \& Sonino, N. (2009). Psychosomatic Assessment. Psychotherapy and Psychosomatics, 78(6), 333-341. Retrieved from http://content.karger.com/ProdukteDB/produkte.asp?Ak tion $=$ Ausgabe $\&$ Ausgabe $=251857 \&$ ProduktNr=223864 . doi:10.1159/000235736.

Figueira, M. L., \& Ouakinin, S. (2008). From psychosomatic to psychological medicine: what's the future? Current Opinion in Psychiatry, 21(4), 412-416. Retrieved from http://journals. lww.com/copsychiatry/Abstract/2008/07000/From_psychosom atic_to_psychological_medicine_.21.aspx

Forghieri, Y. C. (2002). Psicologia fenomenológica: fundamentos, método e pesquisas. São Paulo: Pioneira Thomsom Learning. (Trabalho original publicado em 1993)

Fortes, S., Brasil, M., Garcia-Campayo, J., \& Botega, N. (2006). Somatização. In N. Botega (Org.), Prática psiquiátrica no hospital geral: interconsulta e emergência (2a ed). (pp. 305-324). Porto Alegre: Artmed.

Giannoti, A. (1998). Inserção da psicossomática na prática em saúde pública. Revista da Sociedade de Cardiologia do Estado de $S P, 8$ (1 - supl. A), 9-13.

Giorgi, A. (2009). The descriptive phenomenological method in psychology. Pittsburg: Duquesne Univesity Press.

Guedes, C. R., Nogueira, M. I., \& Camargo Jr, K. R. (2008). Os sintomas vagos e difusos em biomedicina: uma revisão da literatura. Ciência \& Saúde Coletiva, 13(1), 135-144. doi: 10.1590/S1413-81232008000100018 
Hartman, T. C., Lucassen, P. L., De Lisdonk, E.H, \& van Weel, C. (2004). Chronic functional somatic symptoms:a single syndrome? British Journal of General Practice, 54(509), 922-927. Retrieved from http://www.ingentaconnect.com/content/rcgp/ bjgp/2004/00000054/00000509/art00011

Heidbreder, E. (1981). Psicologias do século XX (5 $5^{\mathrm{a}}$ ed., Lauro S. Blandy, Trad.). São Paulo: Mestre Jou. (Trabalho original publicado em 1933)

Hoyos, M. L., Ochoa, D. A., \& Londoño, C. R. (2008). Revisión crítica del concepto "psicosomático" a la luz del dualismo mente-cuerpo. Pensamiento Psicológico, 4(10), 137-147. Retrieved from http://redalyc.uaemex.mx/src/inicio/ArtPdfRed. jsp?iCve $=80111670009$

Kanaan, R. A., Lepine, J. P., \&. Wessely, S. C. (2007). The Association or Otherwise of the Functional Somatic Syndromes Psychosomatic Medicine, 69(9), 855-859. Retrieved from http://www.ncbi.nlm.nih.gov/pmc/articles/PMC2575798/. doi:10.1097/PSY.0b013e31815b001a

Lipowski, Z. J. (1986). Psychosomatic medicine: past and present: Current state. Canadian Journal of Psychiatry, 31(1), 8-13. Retrieved from http://www.ncbi.nlm.nih.gov/pubmed/3948111.

Lyketsos, C. G., Huyse, F. J., Gitlin, D. F., \& Levenson, J. L. (2006). Psychosomatic medicine: A new psychiatric subspecialty in the U.S. focused on the interface between psychiatry and medicine. European Journal of Psychiatry, 20 (3), 165171. Retrieved from http://scielo.isciii.es/pdf/ejpen/v20n3/ 165.pdf

Mello Filho, J. (2002). Concepção Psicossomática: visão atual (3a ed). São Paulo: Casa do Psicólogo.

Mello Filho, J. (1992). Introdução. In J. de Mello Filho (Org.), Psicossomática hoje (2a ed). (pp. 19-82). Porto Alegre: Artes Médicas.

Minayo, M. (2010). O desafio do conhecimento. (12 ${ }^{\mathrm{a}}$ ed.). São Paulo: Hucitec.

Palmieri, T. H. (2005). Plantão Psicológico em Hospital Geral: um estudo fenomenológico. Dissertação de Mestrado, Pontifícia Universidade Católica de Campinas, São Paulo.

Pilan, L. A., \& Benseñor, I. M. (2008). Síndromes funcionais somáticas. Revista de Medicina, São Paulo, 87(4), 238-244.
Retrieved from http://www.fm.usp.br/gdc/docs/revistadc_166_ 09-sindrome-funcionais.pdf

Ribeiro, M., \& Amaral, C. (2008). Medicina centrada no paciente e ensino médico: a importância do cuidado com a pessoa e o poder médico. Revista Brasileira de Educação Médica, 32(1), 90-97. Retrieved from http://www.scielo.br/pdf/rbem/v32n1/ 12.pdf

Rovaletti, M. L. (2002). Corporalidad y psicossomática. Vertex Revista Argentina de Psiquiatria, XIII, 241-257.

Sami-Ali. (1992) Pensar o Somático. Imaginário e Patologia. Guide: Artes Gráficas.

Schwartz, M. A. \& Wiggins, O. P. (2010). Psychosomatic medicine and the philosophy of life. Philosophy, Ethics, and $\mathrm{Hu}$ manities in Medicine, 5(2), 1-5. Retrieved from http://www. peh-med.com/content/5/1/2. doi:10.1186/1747-5341-5-2

Tófoli, L. F., Andrade, L. H., \& Fortes, S. (2011). Somatização na América Latina: uma revisão sobre a classificação de transtornos somatoformes, síndromes funcionais e sintomas sem explicação médica: classificação de transtornos somatoformes, síndromes funcionais e sintomas sem explicação médica. Revista Brasileira de Psiquiatria, 33 (Supl I), 59-69. doi: 10.1590/ S1516-44462011000500006

Trombini, G., \& Baldoni, F. (2004). Distúrbios Psicossomáticos: Como restabelecer o equilíbrio entre mente e corpo. São Paulo: Edições Loyola.

Turato, E. (2008). Tratado da metodologia da pesquisa clínico qualitativa. Petrópolis: Vozes.

Volich, R. (2000). Psicossomática (5 $5^{\mathrm{a}}$ ed.). São Paulo: Casa do Psicólogo. 